\title{
Protein Kinase C $\delta$ : a Gatekeeper of Immune Homeostasis
}

\author{
Elisabeth Salzer $^{1} \cdot$ Elisangela Santos-Valente $^{1} \cdot$ Bärbel Keller $^{2} \cdot$ Klaus Warnatz $^{2}$ • \\ Kaan Boztug ${ }^{1,3,4}$ (I)
}

Received: 29 February 2016 / Accepted: 21 July 2016 /Published online: 19 August 2016

(C) The Author(s) 2016. This article is published with open access at Springerlink.com

\begin{abstract}
Human autoimmune disorders present in various forms and are associated with a life-long burden of high morbidity and mortality. Many different circumstances lead to the loss of immune tolerance and often the origin is suspected to be multifactorial. Recently, patients with autosomal recessive mutations in PRKCD encoding protein kinase c delta (PKC 8 ) have been identified, representing a monogenic prototype for one of the most prominent forms of humoral systemic autoimmune diseases, systemic lupus erythematosus (SLE). PKC $\delta$ is a signaling kinase with multiple downstream target proteins and with functions in various signaling pathways. Interestingly, mouse models have indicated a special role of the ubiquitously expressed protein in the control of B-cell tolerance revealed by the severe autoimmunity in Prkcd $^{--}$ knockout mice as the major phenotype. As such, the study of $\mathrm{PKC} \delta$ deficiency in humans has tremendous potential in enhancing our knowledge on the mechanisms of B-cell tolerance.
\end{abstract}

Elisabeth Salzer and Elisangela Santos-Valente contributed equally to this work.

Kaan Boztug

kboztug@cemm.oeaw.ac.at; kaan.boztug@rud.lbg.ac.at

1 CeMM Research Center for Molecular Medicine of the Austrian Academy of Sciences, Lazarettgasse 14 AKH BT 25.3, Vienna, Austria

2 Center for Chronic Immunodeficiency, University Medical Center Freiburg and University of Freiburg, Freiburg, Germany

3 Department of Pediatrics and Adolescent Medicine, Medical University of Vienna, Lazarettgasse 14 AKH BT 25.3, Vienna, Austria

4 Ludwig Boltzmann Institute for Rare and Undiagnosed Diseases and CeRUD Vienna Center for Rare and Undiagnosed Diseases, Vienna, Austria
Keywords PRKCD · systemic lupus erythematosus · autoimmunity $\cdot$ immunodeficiency

\section{Introduction}

Protein kinase $\mathrm{C} \delta(\mathrm{PKC} \delta$ ) is an essential regulator of peripheral B-cell development and a critical regulator of immune homeostasis $[1,2]$. The protein was discovered in 1986 [3, 4], and several studies have addressed its structure and biological functions [5-13]. Complex activation patterns [5, 7-9, $13,14]$ and opposing PKC $\delta$ functions depending on the activating stimuli and the investigated model system have been described $[8,11,12]$.

PKC $\delta$ is ubiquitously expressed and activated in response to a broad variety of stimuli. In response to specific stimuli, several tyrosine residues in $\mathrm{PKC} \delta$ can be phosphorylated by different tyrosine kinases (Fig. 1), leading to individual phosphorylation patterns and possibly differential activation of downstream targets. Among its main roles, $\mathrm{PKC} \delta$ is responsible for the regulation of survival, proliferation, and apoptosis in a variety of cells including lymphocytes (reviewed in [15]) (Fig. 2).

In 2002, Prkcd knockout mice [1, 2] revealed an essential role for this kinase in B-cell homeostasis and tolerance. Due to defective negative selection in germinal centers and autonomous B-cell hyperproliferation in the periphery [2], autoreactive B cells accumulate in these mice. Consequently, Prkcd knockout mice develop systemic autoimmunity evidenced by autoantibodies, immune complex-mediated glomerulonephritis, lymphadenopathy, splenomegaly, and show B-cell infiltration in several organs and tissues [2].

Autoimmune phenomena arise when mechanisms preventing immune responses directed against the selfantigens are impaired [16]. Primary immunodeficiencies 


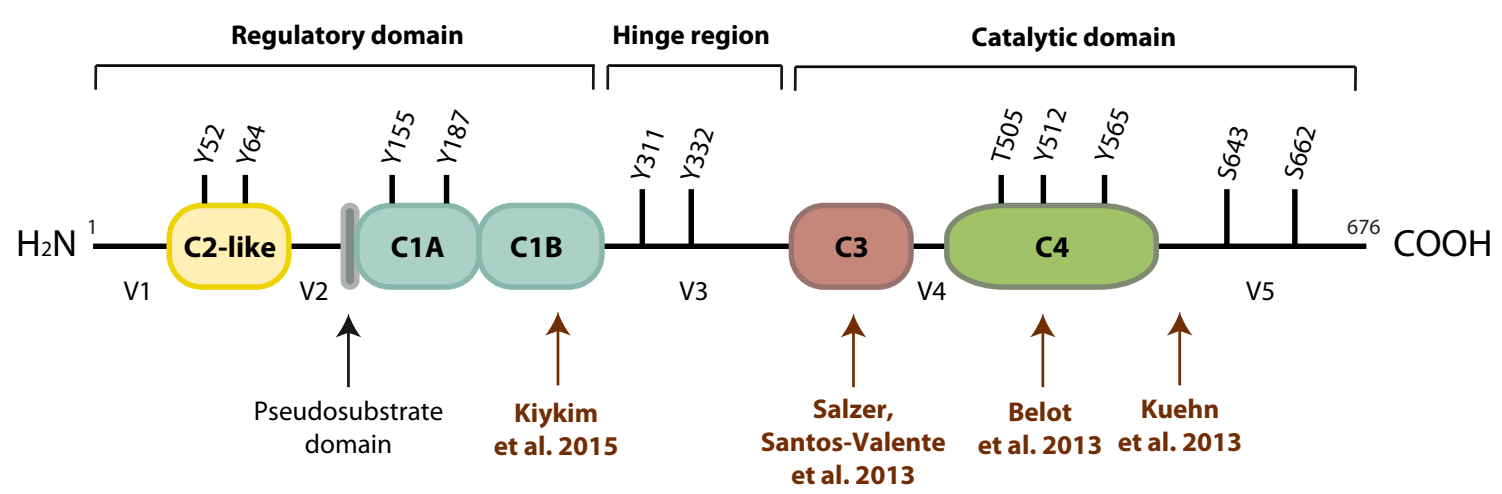

Fig. 1 PKC $\delta$ structure and domains. This figure shows structural domains and phosphorylation sites on PKC $\delta$ as well as the localization of important sequences and the hitherto described PRKCD mutations in humans (modified from atlasgeneticsoncology.org/Genes/GC_PRKCD.html)

(PIDs) are caused by inborn defects in different arms of the immune system and have been described to result in autoimmune manifestations [17]. The clinical phenotype of autoimmune disorders varies greatly depending on the etiology and target organs. Systemic lupus erythematosus (SLE) is a heterogeneous, complex, and multifactorial autoimmune disease caused by defects in innate and adaptive immunity [18] and is characterized by a multifactorial loss of immune tolerance [16]. Given the phenotype of Prkcd knockout mice, a potential role of PKC $\delta$ in the pathogenesis of SLE has been proposed.

The effect of germline mutations affecting PKC $\delta$ in humans and its link to systemic autoimmunity had remained elusive until 2013, when we and others identified human PKC $\delta$ deficiency as a novel PID with severe SLE-like

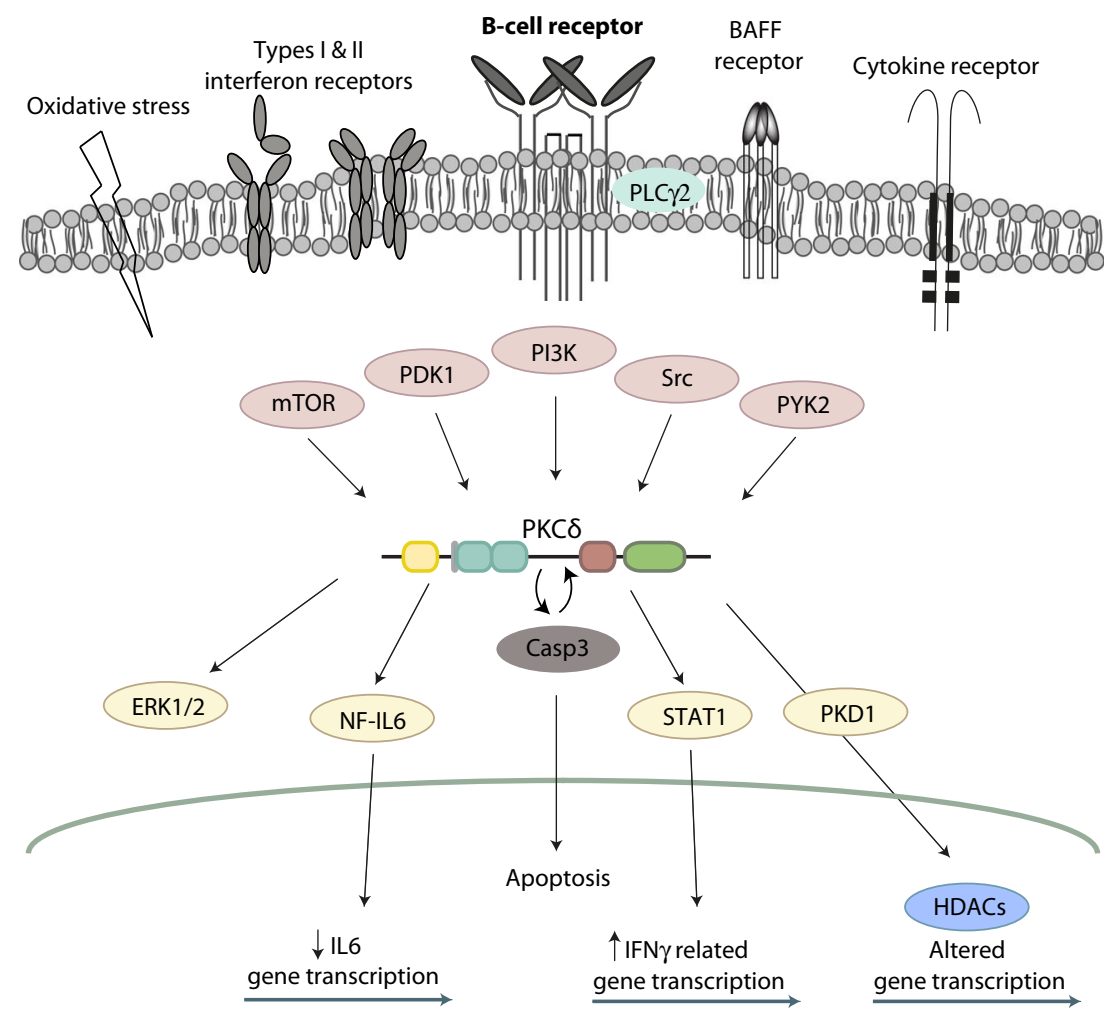

Fig. 2 Overview on $\mathrm{PKC} \delta$ signaling. This figure provides a basic overview of the receptors and molecules involved in PKC $\delta$ activation and of the described PKC $\delta$ activating and inhibitory roles following a variety of stimuli. Functions of PKC $\delta$ in mitochondria are not depicted. More details are outlined in the text. Structures depicted in pink represent upstream and those depicted in yellow represent downstream components involved in PKC 8 activation. mTOR: mechanistic target of rapamycin;
$P D K 1$ : phosphoinositide-dependent kinase-1; PI3K: phosphoinositide 3kinase; $P Y K 2$ : protein tyrosine kinase $2 ; E R K 1 / 2$ : extracellular signalregulated kinases 1 and 2; NF-IL6: nuclear factor of interleukin 6; Casp3: caspase 3; STAT1: signal transducer and activator of transcription 1; $I F N \gamma$ : interferon gamma; $P K D 1$ : protein kinase $\mathrm{D}$ isoform 1 ; HDACs: histone deacetylases 
autoimmunity [19-21]. The following review provides a detailed summary of $\mathrm{PKC} \delta$ protein structure and functions and human $\mathrm{PKC} \delta$ deficiency.

\section{PKC\& Structure, Activation, Regulation, and Role in Apoptosis}

The family of protein kinase C (PKC) contains serine/ threonine kinases that execute key roles in various cellular processes, including cell proliferation, apoptosis, and differentiation [22]. PKC $\delta$ is a $78 \mathrm{kDa}$ and 676 residues long protein included in the group called novel PKCs [3, 4, 23]. It is encoded by the PRKCD gene localized in chromosome 3 in humans and in chromosome 14 in mice [24]. The kinase is structurally divided into a regulatory and a catalytic domain that contains four constant $(\mathrm{C})$ and five variable $(\mathrm{V})$ regions. The variable region 3 (V3), also called hinge region, separates the catalytic and regulatory domains of the protein (reviewed in [15]) (Fig. 1).

The catalytic domain of PKC $\delta$ is required for enzyme activity and includes the $\mathrm{C} 3$ and $\mathrm{C} 4$ domains, encompassing ATP- and substrate-binding sequences, respectively (reviewed in [15]). The regulatory domain contains two constant regions (C1- and C2-like) and a pseudosubstrate. The $\mathrm{C} 1$ domain of $\mathrm{PKC} \delta$ enables its binding to membranes as it contains hydrophobic residues that bind diacylglycerol (DAG) and phorbol 12-myristate 13-acetate (PMA) (reviewed in [6]). As a novel $\mathrm{PKC}, \mathrm{PKC} \delta$ is a calcium-independent, phospholipiddependent kinase containing a C2-like domain, which lacks essential residues that allow conventional PKCs to bind $\mathrm{Ca}^{2+}$ $[10,15]$. Situated between the C1- and C2-like domains, the pseudosubstrate keeps PKC $\delta$ in an inactive folded conformation, blocking access to the substrate-binding pocket (reviewed in [15, 25]).

A broad variety of stimuli lead to PKC $\delta$ activation through phosphorylation of serine/threonine and tyrosine residues, as well as proteolytic cleavage into an active fragment $[14,23]$. Full kinase activity requires autophosphorylation of Ser-643 (turn motif), phosphorylation of Ser-662 (hydrophobic region) mediated by $\mathrm{PKC} \zeta$ or mTOR (mechanistic target of rapamycin), and Thr-505 phosphorylation by PDK1 [8, 9, 13, 14] (Figs. 1 and 2).

Protein activity is also regulated by the phosphorylation of specific tyrosine residues according to the stimuli employed (reviewed in [26]) (Fig. 1). In the hinge region, phosphorylation of Tyr311 and Tyr332 in response to apoptotic agents enables caspase 3 to cleave PKC $\delta$. The proteolytic cleavage of PKC $\delta$ by caspase 3 generates a $40 \mathrm{kDa}$ catalytic active fragment capable of translocating to mitochondria and/or nucleus $[6,14,27]$ and promoting apoptosis $[28,29]$. Apart from conformational changes after binding of DAG and autophosphorylation, activation of PKC $\delta$ depends on Ser/Thr phosphorylation by PDK1 [30]. Also, Src kinase family members, PYK2 as well as growth factor receptors phosphorylate tyrosine residues of $\mathrm{PKC} \delta$ and modulate its enzymatic activity [23, 31] (Fig. 2).

In contrast to most other PKC isoforms, $\mathrm{PKC} \delta$ conveys proapoptotic signals upon a variety of stimuli not only through nuclear but also mitochondrial and cytosolic pathways [32]. When activated, PKC $\delta$ translocates to the nucleus [33] and, possibly through JNK signals, promotes proximal regulation of apoptosis through cytochrome $\mathrm{C}$ release, PARP cleavage, histone phosphorylation [34], and caspase 3 activation. Nuclear retention can be prolonged and intensified by generation of the catalytic fragment of PKC $\delta$ by caspase 3 [33]. Engagement of apoptosis via the mitochondrial pathway has been described in response to the diacylglycerol analog PMA [22]. In brief, PKC $\delta$ phosphorylates phospholipid scramblase 3 (PLS3) at the mitochondrial site, subsequently facilitating mitochondrial targeting of tBid and apoptosis induction [35].

Moreover, in addition to the membrane-bound form of PKC $\delta$, whose phosphorylation is regulated by DAG accumulation and membrane translocation upon PMA, a tyrosinephosphorylated form of PKC $\delta$ is also found in the soluble fraction of cells in response to oxidant stress and display distinct substrate specificity. This PKC $\delta$ form is phosphorylated by Src family kinases and possesses lipid-independent catalytic functions, being able to phosphorylate substrates not only on lipid membranes but also in several compartments of the cell [36] (reviewed in [14]). Description of this lipid-independent kinase provides an explanation to PKC-dependent phosphorylation of substrates outside membrane compartments such as myofibrillar proteins in sarcomeres, structures not associated with lipid membranes [37] (reviewed in [14]).

Although numerous studies have tried to elucidate $\mathrm{PKC} \delta$ activation and biological functions, its complex activation patterns and roles in various pathways remains incompletely understood.

\section{PKC $\delta$ Signaling and Functions in Lymphocytes}

In B cells, recent evidence suggests a PKC $\delta$-, RASGRP-, and calcium-dependent ERK signaling as a critical proapoptotic pathway promoting negative selection [38] (Fig. 2). This pathway is biochemically distinct from DAG-induced ERK activation. Moreover, $\mathrm{PKC} \delta$ phosphorylation and activity plays a central role in the BCR-signalosome-independent, IL-4dependent activation of B cells [39], adding another level of complexity to the regulation of survival, proliferation, and apoptosis by $\mathrm{PKC} \delta$.

After binding of B-cell activating factor (BAFF) to its receptor and after $\mathrm{B}$-cell receptor (BCR) stimulation, $\mathrm{PKC} \delta$ is phosphorylated at Thr505 [38, 40, 41] involving activation of the PI3K [41]. In the absence of PKC 8 , both tonic 
(ligand-independent) and antigen receptor-induced $\mathrm{BCR}$ signaling is increased [38]. Additionally, a PI3K-/PKC $\beta$ independent alternative pathway downstream of the $\mathrm{BCR}$ is induced after prestimulation of B cells with IL-4 [42]. In contrast to the classical signalosome-dependent pathway, it requires the direct interaction of LYN, inducing phosphorylation of PKC $\delta$ at Tyr311 and resulting in increased phosphorylation of protein kinase D (PKD) [39]. Downstream of PKD, histone deacetylases (HDAC) 5 and 7 are phosphorylated and excluded from the nucleus, thereby facilitating the transcription of genes, which are repressed by these HDACs [39]. The specific targets of these class IIa HDACs in B lymphocytes have not been investigated in detail but include MEF2-dependent promoters [43] playing a substantial role in B-cell proliferation and survival [44]. In vitro studies demonstrated the interference of HDAC inhibition with plasmablast differentiation [45]. HDACs may also be involved downstream of PKC $\delta$ in the expression of CIITA which regulates MHC class II expression [46] (Fig. 2).

In T cells, $\mathrm{PKC} \delta$ has a negative role in TCR/CD3-mediated IL-2 production and in T-cell proliferation with consequent increased signaling responses in $\mathrm{PKC}^{-/-} \mathrm{T}$ cells [47]. Its importance to ERK pathway signaling in $\mathrm{T}$ cells has also been demonstrated as lack of T-cell PKC $\delta$ activity prompts reduced ERK signaling [48].

Until now, critical roles for PKC $\delta$ in regulation of survival, proliferation, and apoptosis, mainly of $\mathrm{B}$ cells, have been recognized, although more comprehensive studies are still necessary to fully elucidate its complex functions in lymphocytes.

\section{PKC\& Deficiency in Mice}

Differentiation and development of lymphocytes in the bone marrow of Prkcd-deficient mice was reported normal [49]. Also, peripheral T- and NK-cell development seemed unaffected [49]. However, in peripheral blood and secondary lymphoid organs, these mice showed an increased frequency of mature B cells, which could be attributed to autocrine IL-6 driven proliferation $[1,2]$, since PKC $\delta$ negatively interferes with the production of this cytokine through phosphorylation of the nuclear factor (NF)-IL6 (2) (Fig. 2).

In consequence, mice with mutations in Prkcd develop severe humoral autoimmunity, marked by autoantibodies, immune complex-mediated glomerulonephritis, lymphadenopathy, splenomegaly, and B cell infiltrations in kidney, liver, lung, and salivary glands, respectively [2]. In a hen-egglysozyme transgenic mouse model, it has been shown that the induction of anergy and thus peripheral tolerance toward soluble self-antigens was impaired, while the deletion of antigen-specific B cells by membrane-bound self-antigens was not affected in the absence of PKC $\delta$ [1]. More recently,
Limnander et al. were able to elucidate impaired BCRinduced apoptosis at the T1 B cell stage as the major mechanism contributing to defective peripheral tolerance and overt autoimmunity in the absence of PKC $\delta$ [38].

Transgenic mice expressing doxycycline-induced dominant negative PKC $\delta$ in T cells show reduced ERK pathway signaling, decreased expression of Dnmt1, and increased expression of methylation-sensitive genes. Such mice presented with lupus-like autoimmunity including anti-double-stranded DNA (dsDNA) antibodies and immune complex glomerulonephritis [48]. Thus, $\mathrm{PKC} \delta$ deficiency is associated with a loss of tolerance in peripheral B-cell development and possibly also increased T-cell activation, causing systemic autoimmunity in these mice $[1,2,48]$.

In brief, studies in PKC $\delta$-deficient mice revealed nonredundant roles for this kinase in B-cell proliferation and peripheral tolerance as well as in T-cell activation.

\section{PKCס in Human Systemic Lupus Erythematosus}

Systemic lupus erythematosus is mainly an immune complexmediated disease characterized by the presence of multiple autoantibodies including antinuclear antibodies (ANAs). The loss of immune tolerance in SLE is multifactorial and includes a breakdown of T- and B-cell tolerance [16]. Given the phenotype of Prkcd knockout mice, a potential role of PKC $\delta$ in the pathogenesis of SLE could be proposed. Gorelik et al. [48, $50,51]$ postulated that inhibition of PKC $\delta$ and disturbed ERK signaling in T cells are involved in the development of autoimmunity in active SLE. Reduction of $\mathrm{PKC} \delta$ phosphorylation at Thr505 due to oxidative stress and nitration of PKC $\delta$ prompts decreased ERK signaling in T cells of SLE patients, which leads to reduced DNMT1 activity and hypomethylation of regulatory sequences of sensitive genes such as LFAI (encoding CD11a) and TNFSF7 (encoding CD70), therefore causing T-cell activation and contributing to T-cell autoimmunity. This model was corroborated by the occurrence of druginduced lupus by demethylating drugs like hydralazine and others [52].

Interestingly, comparative network analysis of the phosphoproteomes of peripheral blood mononuclear cells of SLE patients versus healthy controls described PKC $\delta$ (beside Src kinases, the NF-kB signaling component RelA and HDAC1) as one of the genes with the most connections to other proteins in the altered network of SLE patients and therefore with significant role in the network stability [53].

In addition, a link between IFN signaling and PKC $\delta$ was established by the association of PKC $\delta$ activity with STAT1 activation through Ser727 phosphorylation, which is essential for the expression of IFN response genes [54, 55] (Fig. 2). Huang et al. demonstrated that IFN-alpha-induced expression of IFIT4 requires activation of PKC $\delta$ and JNK, as well as 
STAT1 phosphorylation at Ser727 [56]. Thus, a decreased activity of PKC $\delta$ in SLE monocytes may contribute to the proinflammatory effect ascribed to IL-10 in SLE [57]. However, in conditions with elevated levels of IFN type I cytokines such as during infections or in autoimmune diseases, PKC $\delta$ shows opposite activity, suppressing IL-10 activation of STAT1 through tyrosine phosphorylation [57].

Given the multiple activities of PKC $\delta$, among others in Tcell activation and IFN signaling, it is not surprising that an altered PKC $\delta$ function contributes, probably through several mechanisms, to the complex autoimmunity observed in SLE.

\section{Human PKC $\delta$ Deficiency: Genetics and Clinical Phenotype}

In our previous work, we identified a patient (P1) with an autosomal recessive disorder caused by loss-of-function splice-site mutation in PRKCD (c.1352+1G > A) (Fig. 1), within the catalytic domain of the protein, whose clinical picture included antibody deficiency with respiratory tract infections from the first year of life and immune dysregulation reminiscent of a CVID-like disease [21]. Partial clinical improvement could be achieved with the initiation of immunoglobulin $\mathrm{G}$ substitution at the age of 4 years. Features of immune dysregulation, including autoimmunity and lymphoproliferation, initiated equally early in life, with membranous glomerulonephritis, generalized enlargement of lymphoid organs, relapsing polychondritis and antiphospholipid syndrome. Autoreactive antibodies including ANA could be detected during laboratory investigation, while isohemagglutinins were absent. Important findings in the B-lymphocyte compartment were progressive reduction of CD19+ cells, impaired class switch, reduced numbers of memory B-cells, and increased CD21 $1^{\text {low }}$ B-cells (Table 1).

Since our initial description of PKC $\delta$ deficiency in 2013, five other patients ( $\mathrm{P} 2$ to $\mathrm{P} 6$ ) from three unrelated kindred also bearing biallelic mutations in PRKCD have been published $[19,20,58]$ (Table 1). The mutations described were located in the nuclear localization sequence of $P R K C D$ (c. $1840 \mathrm{C}>\mathrm{T}$; p.R614W; P2) [20], inside the activation loop (c.1258G $>$ A; p.G510S; P3 to P5) [19] or within the regulatory domain (c.742G>A; p.G248S; P6) [58] (Fig. 1; Table 1). Similar to our patient, all those mutations led to absence or reduction of $\mathrm{PKC} \delta$ expression.

The clinical manifestations of $\mathrm{P} 2$ were similar to our patient and he was diagnosed with an autoimmune lymphoproliferative syndrome (ALPS)-like disease [20]. In the same year, three PKC $\delta$-deficient siblings (P3 to P5) diagnosed with SLE were reported presenting with lymphadenopathy, hepatosplenomegaly, nephritis, and arthritis [19]. In 2015, we and others described another patient (P6) with erythematous skin rash accompanied by fever and thrombocytopenia. Physical examination at that time point revealed partial alopecia, hyperpigmented skin rash predominantly in sun-exposed areas, cervical lymphadenopathy, hepatosplenomegaly, and mild hypotonia [58].

All six hitherto described patients showed symptoms before the age of 10 years and presented with hepatosplenomegaly, lymphoproliferation, autoreactive antibodies, and SLE or SLElike autoimmunity. Lymphoproliferative features were seen in five patients from the four kindred (P1 to P4, P6), kidney involvement was present in four patients from two families (P1 and $\mathrm{P} 3$ to $\mathrm{P} 5)$, and recurrent infections were observed in $\mathrm{P} 1$ and P2 (Table 1).

Laboratory investigations in all patients revealed the presence of autoantibodies and mostly unaltered T-cell numbers and function (Table 1). Only P2 presented with increased double-negative T cells. P2 also showed severely impaired NK-cell function, while NK cells from P6 demonstrated moderate decrease in cytolytic activity. Circulating B-lymphocyte counts were variable among the affected individuals, three out of six patients showing reduced or progressively reduced CD19+ cells (P1, P3, and P4). IgG memory B cells were reduced in the peripheral blood of all the patients, while predominant B-cell infiltration was apparent in peripheral lymphoid organs of two patients with lymphadenopathy and splenomegaly (P1 and P2). Four out of six $\mathrm{PKC} \delta$-deficient patients presented with nephritis (P1, P3-P5), and two patients had reduced levels of $\mathrm{C} 3$ and $\mathrm{C} 4$ (P3 and P4). Immunoglobulin levels were variable but three patients presented with elevated IgM levels (P1 and P2, P6) (Table 1).

Additional experiments demonstrated that cells bearing the $P R K C D$ c. $1352+1 \mathrm{G}>$ A or c. $742 \mathrm{C}>\mathrm{A}$ mutation showed reduced expression or activation of the PKC substrate MARCKS [59]. B cells from P1 (c.1352 + 1G>A) displayed increased NF-IL6 and $I L-6$ mRNA levels. B lymphocytes from P2 (c. 1840C $>$ T) showed slightly increased IL-6 and increased IL-10 levels. Decreased apoptosis and increased response to stimulation were demonstrated on B cells carrying $P R K C D$ c. $1840 \mathrm{C}>\mathrm{T}$ or $\mathrm{c} .1258 \mathrm{G}>\mathrm{A}$ mutation. Both of these Epstein-Barr virus immortalized lymphoblastic B-cell lines were characterized by B-cell hyperproliferative responses and resistance to PMA-induced or calcium-dependent apoptosis.

The phenotype resulting from autosomal recessive $\mathrm{PKC} \delta$ deficiency in humans expands findings obtained from mice related to the functions of the protein in B-cell development and activity [1]. A non-essential role for the protein in embryonic development or early survival had been suggested from mouse studies [1,2]; however, presence of PKC $\delta$ is crucial for controlling B-cell expansion, considering that both human patients and mice presented with lymphadenopathy and/or hepatosplenomegaly [2, 19-21]. Moreover, increased apoptosis resistance of $\mathrm{B}$ cells derived from patients with mutations in $P R K C D$ was demonstrated, when compared to wild-type 


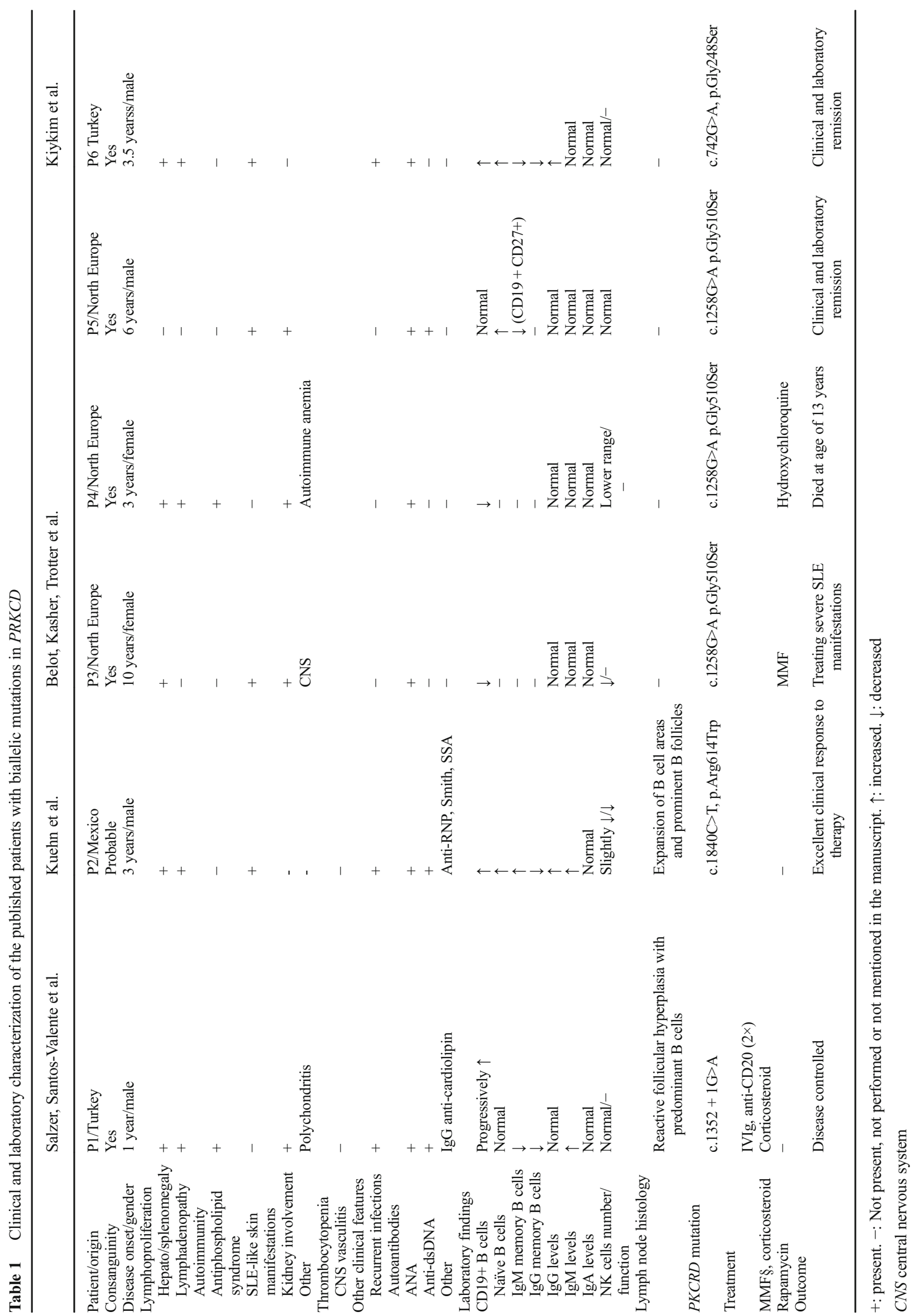


cells $[19,20]$. In human PKC $\delta$ deficiency as well as in Prkcd $^{\prime}$ mice, B cells also produced increased amounts of the proinflammatory cytokine IL-6 compared to wild type, probably due to inhibition of NF-IL6 DNA binding activity [2, 20, 21]. Additionally, the production of autoreactive antibodies by plasma cells was significantly increased in mouse models $[1,2]$ and in all described patients [19-21].

The involvement of IL- 6 in disturbed B-cell tolerance observed in patients with $P R K C D$ mutation is supported by their phenotypical similarities with mice transgenically expressing human IL-6, including glomerulonephritis and enlargement of lymphoid organs due to massive B-lymphocyte proliferation [60]. Specifically, the uncontrolled B-cell proliferation observed in individuals with loss-of-function PRKCD mutations may however also relate to the already-mentioned decreased inhibition of IL-10 proinflammatory activity in the absence of functional PKC $\delta$ [57].

Although the impact of $\mathrm{PKC} \delta$ deficiency in T-cell activation and proliferation could not be demonstrated for the patients described, and the influence of these mutations in NKcell activity is yet to be understood, findings from mouse models expanded by human $\mathrm{PKC} \delta$-deficient patients validate the crucial role of $\mathrm{PKC} \delta$ in controlling B-cell activation, differentiation, and apoptosis.

\section{PKCठ Deficiency as a Molecular Cause of Systemic Autoimmunity}

The clinical phenotype of SLE is often variable, which suggests a heterogeneous pathophysiology of this disease [18]. To date, the etiology of SLE is still unclear; however, its pathogenesis has been associated with defective clearance of apoptotic cells, disturbed B- and T-cell activation, and cytokinemediated inflammation. Clinically, almost half of the SLE patients present with malar rash and one third with nephritis (reviewed in [61]). The presence of anti-dsDNA antibodies is associated with higher risk of nephropathy and hemolytic anemia while presence of anti-cardiolipin antibodies and lupus anticoagulant are associated with thromboembolic events and miscarriage. Childhood-onset SLE patients, who are more likely to suffer from monogenic diseases, mainly present with severe nephropathy but also neurologic features, thrombocytopenia, and hemolytic anemia [62]. Clinically, typical features of nephritis, butterfly rash as well as anti-dsDNA antibodies demonstrated in the PKC $\delta$-deficient patients are reminiscent of childhood-onset SLE [63].

Given the fact that PKC $\delta$ is crucial in the regulation of Bcell survival and apoptosis during B-cell development, the importance of intact B-cell signaling for peripheral tolerance is evident. Consistent with high concentrations of autoreactive antibodies, histology analyses of kidneys in $\mathrm{Prkcd}^{--}$mice indicate glomerulonephritis with mesangial cell proliferation and deposition of $\mathrm{IgG}$ and complement component $\mathrm{C} 3$, similarly to the findings of nephritis and reduced levels of $\mathrm{C} 3$ and C4 in some of the PKC $\delta$-deficient patients [19, 21].

Therefore, it is not surprising that also patients with common variable immunodeficiency (CVID) show increased susceptibility to immune dysregulation including autoimmunity, lymphoproliferation, and malignancies [64-68]. In CVID patients, autoimmunity is identified as the second most frequent manifestation after pneumonia [69], often closely associated with splenomegaly $[69,70]$. Interestingly, the increased $\mathrm{CD} 21^{\text {low }}$ B-cells and decreased memory B-cells displayed by $\mathrm{PKC} \delta$-deficient patients resemble findings of the subgroup CVID Ia from the Freiburg classification [71], which presents with impaired BCR-mediated calcium response [72] and shows higher frequency of splenomegaly and autoimmune cytopenias [71, 72].

The importance of this pathway in B-cell homeostasis could be further substantiated by the discovery of CVID-like B cell-deficient patients with or without autoimmunity carrying PLCG2 mutations [67, 68]. PLC $\gamma 2$ is an essential phospholipase downstream of the BCR upstream of PKC [63], catalyzing the conversion of 1-phosphatidyl-1D-myo-inositol 4,5-bisphosphate to 1D-myo-inositol 1,4,5-trisphosphate (IP3) and DAG using calcium as a cofactor [73].

Since PKC $\delta$ is required not only to regulate T-cell activation but also to intact B-cell signaling in the periphery and consequently to peripheral tolerance; disturbed activity of this kinase can most invariably prompt systemic autoimmune features as seen in other B-cell PIDs and in SLE.

\section{Concepts of SLE Therapy in Light of PKC $\delta$ Deficiency}

Current treatment strategies in SLE are purely based on empirical observations. With the discovery of (mono)genetic defects underlying SLE pathology, different therapeutic options may come into place. Currently, standard treatments in SLE comprise hydroxychloroquine or other antimalarial agents; corticosteroids, which were also included in the treatment of P1 and P2 [20, 21]; and cytotoxic immunosuppressive drugs [74]. Interestingly, patient P6 showed amelioration of autoimmunity upon treatment using hydroxychloroquine [58]. The proposed molecular mechanism to justify the immunosuppression observed is an increase of CTLA4 expression, as demonstrated in LRBA-deficient patients treated with chloroquine [75].

Other effective drugs frequently used in such patients are mycophenolate mofetil (MMF) and rapamycin. P1 and P5 received MMF, and $\mathrm{P} 2$ was treated with rapamycin, all leading to disease control/clinical remission [19-21] (Table 1). Rapamycin is an inhibitor of mTOR, a central serinethreonine kinase for cellular metabolism, inflammation, and 
antigenic responses in several tissues [76], involved in the phosphorylation of the hydrophobic region of PKC $[13]$.

Rituximab is a monoclonal antibody targeting the surface molecule CD20, expressed by mature B cells. It is effective in treatment of B-cell malignancies and rheumatoid arthritis, but the effects on SLE manifestations are still controversial, although approved in Europe and America for use as treatment of refractory patients [74]. Two courses of this drug were employed in P1; however, upon reoccurrence of peripheral blood $\mathrm{B}$ cells, autoantibody production was again detectable [21]. However, as rituximab targets all CD20-positive cells and does not influence selection of B cells, targeting of BAFF using belimumab would have been an interesting strategy, as BAFF signals are influenced by PKC $\delta$ and the survival factor adds to the selection process by altering apoptosis of transitional B cells.

Similarly to patients with active SLE [77], some patients with PRKCD mutation present with high levels of serum IL-6 and/or IL-10 [20, 21]. Tocilizumab is a humanized monoclonal antibody that prevents IL-6 binding and therefore blocks its proinflammatory functions. In our own experience on clinical treatment of patient P1, tocilizumab was efficient in reducing clinical and laboratory findings associated with autoimmunity; however, infectious complications prevented longterm use of therapy (unpublished results). Future studies will need to systematically assess blockade of IL-6 signaling as a therapeutic option in $\mathrm{PKC} \delta$ deficiency.

Recent improvements in hematopoietic stem cell transplantation (HSCT) and gene therapy techniques have led to their increased use for potentially curative treatment of patients with severe PIDs [78-80]. Although clinical studies on HSCT in non-SCID are ongoing, it is still unclear which patients should undergo HSCT according to their phenotype/genotype, which conditioning regimen to choose, and how to manage those patients presenting with autoimmune diseases [79].

Recent advances in molecular diagnosis and treatment options therefore enable improved targeted therapies to be employed for the treatment of systemic autoimmunity in light of the identified molecular pathomechanism affected.

\section{Summary}

The essential functions of PKC $\delta$ in B-cell homeostasis, in Tcell activation and proliferation, and more specifically in the autoimmune features observed in SLE were demonstrated in Prkcd-deficient mice (or mouse T-cells) leading to systemic autoimmunity. Recently identified human autosomal recessive $\mathrm{PKC} \delta$ deficiency prompts severe symptoms including hepatosplenomegaly, lymphoproliferation, and SLE or SLElike autoimmunity early in life. Such findings expand those of Prkcd-deficient mice in regard to the roles of this kinase in Bcell survival and apoptosis and implicate PKC $\delta$ and intact B- cell signaling in peripheral tolerance in humans. Taken together, the identification of human PKC $\delta$ deficiency provided proofof-concept for monogenetic forms of early-onset SLE and allowed the identification of a key molecular pathomechanism relevant to generation of autoimmunity in humans.

Acknowledgments Open access funding provided by Medical University of Vienna.

\section{Compliance with Ethical Standards}

Conflict of Interest The authors declare that they have no conflict of interest.

Open Access This article is distributed under the terms of the Creative Commons Attribution 4.0 International License (http:// creativecommons.org/licenses/by/4.0/), which permits unrestricted use, distribution, and reproduction in any medium, provided you give appropriate credit to the original author(s) and the source, provide a link to the Creative Commons license, and indicate if changes were made.

\section{References}

1. Mecklenbrauker I, Saijo K, Zheng NY, Leitges M, Tarakhovsky A. Protein kinase Cdelta controls self-antigen-induced B-cell tolerance. Nature. 2002;416(6883):860-5.

2. Miyamoto A, Nakayama K, Imaki H, Hirose S, Jiang Y, Abe M, et al. Increased proliferation of B cells and auto-immunity in mice lacking protein kinase Cdelta. Nature. 2002;416(6883):865-9.

3. Ono Y, Fujii T, Ogita K, Kikkawa U, Igarashi K, Nishizuka Y. Identification of three additional members of rat protein kinase $\mathrm{C}$ family: delta-, epsilon- and zeta-subspecies. FEBS Lett. 1987;226(1):125-8.

4. Gschwendt M, Kittstein W, Marks F. A novel type of phorbol esterdependent protein phosphorylation in the particulate fraction of mouse epidermis. Biochem Biophys Res Commun. 1986;137(2): 766-74.

5. Blake RA, Garcia-Paramio P, Parker PJ, Courtneidge SA. Src promotes PKCdelta degradation. Cell Growth Differ. 1999;10(4):23141.

6. Cho W. Membrane targeting by $\mathrm{C} 1$ and $\mathrm{C} 2$ domains. J Biol Chem. 2001;276(35):32407-10.

7. Konishi H, Tanaka M, Takemura Y, Matsuzaki H, Ono Y, Kikkawa $\mathrm{U}$, et al. Activation of protein kinase $\mathrm{C}$ by tyrosine phosphorylation in response to H2O2. Proc Natl Acad Sci U S A. 1997;14(21): 11233-7.

8. Kronfeld I, Kazimirsky G, Lorenzo PS, Garfield SH, Blumberg PM, Brodie C. Phosphorylation of protein kinase Cdelta on distinct tyrosine residues regulates specific cellular functions. J Biol Chem. 2000;275(45):35491-8.

9. Kumar V, Pandey P, Sabatini D, Kumar M, Majumder PK, Bharti A, et al. Functional interaction between RAFT1/FRAP/mTOR and protein kinase cdelta in the regulation of cap-dependent initiation of translation. EMBO J. 2000;19(5):1087-97.

10. Pappa H, Murray-Rust J, Dekker LV, Parker PJ, McDonald NQ. Crystal structure of the $\mathrm{C} 2$ domain from protein kinase C-delta. Structure. 1998;6(7):885-94. 
11. Sun X, Wu F, Datta R, Kharbanda S, Kufe D. Interaction between protein kinase $\mathrm{C}$ delta and the c-Abl tyrosine kinase in the cellular response to oxidative stress. J Biol Chem. 2000;275(11):7470-3.

12. Szallasi Z, Denning MF, Chang EY, Rivera J, Yuspa SH, Lehel C, et al. Development of a rapid approach to identification of tyrosine phosphorylation sites: application to PKC delta phosphorylated upon activation of the high affinity receptor for $\operatorname{IgE}$ in rat basophilic leukemia cells. Biochem Biophys Res Commun. 1995;214(3):888-94.

13. Ziegler WH, Parekh DB, Le Good JA, Whelan RD, Kelly JJ, Frech $\mathrm{M}$, et al. Rapamycin-sensitive phosphorylation of PKC on a carboxy-terminal site by an atypical PKC complex. Curr Biol. 1999;9(10):522-9.

14. Steinberg SF. Distinctive activation mechanisms and functions for protein kinase Cdelta. Biochem J. 2004;384(Pt 3):449-59.

15. Duquesnes N, Lezoualc'h F, Crozatier B. PKC-delta and PKC-epsilon: foes of the same family or strangers? J Mol Cell Cardiol. 2011;51(5):665-73.

16. Wahren-Herlenius M, Dorner T. Immunopathogenic mechanisms of systemic autoimmune disease. Lancet. 2013;382(9894):819-31.

17. Dosanjh A. Autoimmunity and Immunodeficiency. Pediatr Rev Am Acad Pediatr. 2015;36(11):489-95.

18. Tsokos GC. Systemic lupus erythematosus. N Engl J Med. 2011;365(22):2110-21.

19. Belot A, Kasher PR, Trotter EW, Foray AP, Debaud AL, Rice GI, et al. Protein kinase cdelta deficiency causes Mendelian systemic lupus erythematosus with B cell-defective apoptosis and hyperproliferation. Arthritis Rheum. 2013;65(8):2161-71.

20. Kuehn HS, Niemela JE, Rangel-Santos A, Zhang M, Pittaluga S, Stoddard JL, et al. Loss-of-function of the protein kinase C delta (PKCdelta) causes a B-cell lymphoproliferative syndrome in humans. Blood. 2013;121(16):3117-25.

21. Salzer E, Santos-Valente E, Klaver S, Ban SA, Emminger W, Prengemann NK, et al. B-cell deficiency and severe autoimmunity caused by deficiency of protein kinase $\mathrm{C}$ delta. Blood. 2013;121(16):3112-6.

22. Wu-Zhang AX, Murphy AN, Bachman M, Newton AC. Isozymespecific interaction of protein kinase Cdelta with mitochondria dissected using live cell fluorescence imaging. J Biol Chem. 2012;287(45):37891-906.

23. Kikkawa U, Matsuzaki H, Yamamoto T. Protein kinase $\mathrm{C}$ delta (PKC delta): activation mechanisms and functions. J Biochem. 2002;132(6):831-9.

24. Huppi K, Siwarski D, Goodnight J, Mischak H. Assignment of the protein kinase $\mathrm{C}$ delta polypeptide gene (PRKCD) to human chromosome 3 and mouse chromosome 14. Genomics. 1994;19(1): $161-2$.

25. Rosse C, Linch M, Kermorgant S, Cameron AJ, Boeckeler K, Parker PJ. PKC and the control of localized signal dynamics. Nat Rev Mol Cell Biol. 2010;11(2):103-12.

26. Yoshida K. PKCdelta signaling: mechanisms of DNA damage response and apoptosis. Cell Signal. 2007;19(5):892-901.

27. Hurley JH, Misra S. Signaling and subcellular targeting by membrane-binding domains. Annu Rev Biophys Biomol Struct. 2000;29:49-79.

28. Ghayur T, Hugunin M, Talanian RV, Ratnofsky S, Quinlan C, Emoto Y, et al. Proteolytic activation of protein kinase $\mathrm{C}$ delta by an ICE/CED 3-like protease induces characteristics of apoptosis. J Exp Med. 1996;184(6):2399-404.

29. Emoto Y, Manome Y, Meinhardt G, Kisaki H, Kharbanda S, Robertson M, et al. Proteolytic activation of protein kinase $\mathrm{C}$ delta by an ICE-like protease in apoptotic cells. EMBO J. 1995;14(24): 6148-56.

30. Durgan J, Michael N, Totty N, Parker PJ. Novel phosphorylation site markers of protein kinase $\mathrm{C}$ delta activation. FEBS Lett. 2007;581(18):3377-81.
31. Basu A, Pal D. Two faces of protein kinase Cdelta: the contrasting roles of PKCdelta in cell survival and cell death. ScientificWorldJournal. 2010;10:2272-84.

32. Gomel R, Xiang C, Finniss S, Lee HK, Lu W, Okhrimenko H, et al. The localization of protein kinase Cdelta in different subcellular sites affects its proapoptotic and antiapoptotic functions and the activation of distinct downstream signaling pathways. Mol Cancer Res. 2007;5(6):627-39.

33. DeVries-Seimon TA, Ohm AM, Humphries MJ, Reyland ME. Induction of apoptosis is driven by nuclear retention of protein kinase C delta. J Biol Chem. 2007;282:22307-14. doi:10.1074 /jbc.M703661200.

34. Park $\mathrm{CH}$, Kim KT. Apoptotic phosphorylation of histone $\mathrm{H} 3$ on Ser-10 by protein kinase Cdelta. PLoS One. 2012;7:e44307. doi:10.1371/journal.pone.0044307.

35. He Y. Phosphorylation of mitochondrial phospholipid scramblase 3 by protein kinase $\mathrm{C}$-delta induces its activation and facilitates mitochondrial targeting of tBid. J Cell Biochem. 2007;101:1210-21. doi:10.1002/jcb.21243.

36. Rybin VO, Guo J, Sabri A, Elouardighi H, Schaefer E, Steinberg SF. Stimulus-specific differences in protein kinase $\mathrm{C}$ delta localization and activation mechanisms in cardiomyocytes. J Biol Chem. 2004;279(18):19350-61.

37. Solaro RJ, Burkart EM. Functional defects in troponin and the systems biology of heart failure. J Mol Cell Cardiol. 2002;34(7): 689-93.

38. Limnander A, Zikherman J, Lau T, Leitges M, Weiss A, Roose JP. Protein kinase cdelta promotes transitional B cell-negative selection and limits proximal $\mathrm{B}$ cell receptor signaling to enforce tolerance. Mol Cell Biol. 2014;34(8):1474-85.

39. Guo B, Rothstein TL. A novel Lyn-protein kinase Cdelta/epsilonprotein kinase $\mathrm{D}$ axis is activated in $\mathrm{B}$ cells by signalosomeindependent alternate pathway BCR signaling. Eur J Immunol. 2013;43(6):1643-50.

40. Barbazuk SM, Gold MR. Protein kinase C-delta is a target of B-cell antigen receptor signaling. Immunol Lett. 1999;69(2):259-67.

41. Popoff IJ, Deans JP. Activation and tyrosine phosphorylation of protein kinase $\mathrm{C}$ delta in response to $\mathrm{B}$ cell antigen receptor stimulation. Mol Immunol. 1999;36(15-16):1005-16.

42. Rothstein TL, Guo B. Receptor crosstalk: reprogramming B cell receptor signalling to an alternate pathway results in expression and secretion of the autoimmunity-associated cytokine, osteopontin. J Intern Med. 2009;265(6):632-43.

43. Martin M, Kettmann R, Dequiedt F. Class IIa histone deacetylases: regulating the regulators. Oncogene. 2007;26(37):5450-67.

44. Wilker PR, Kohyama M, Sandau MM, Albring JC, Nakagawa O, Schwarz JJ, et al. Transcription factor Mef2c is required for B cell proliferation and survival after antigen receptor stimulation. Nat Immunol. 2008;9(6):603-12.

45. Kienzler AK, Rizzi M, Reith M, Nutt SL, Eibel H. Inhibition of human B-cell development into plasmablasts by histone deacetylase inhibitor valproic acid. J Allergy Clin Immunol. 2013;131(6):1695-9.

46. Kwon MJ, Soh JW, Chang CH. Protein kinase C delta is essential to maintain CIITA gene expression in B cells. J Immunol. 2006;177(2):950-6.

47. Gruber T, Barsig J, Pfeifhofer C, Ghaffari-Tabrizi N, Tinhofer I, Leitges $\mathrm{M}$, et al. PKCdelta is involved in signal attenuation in CD3+ T cells. Immunol Lett. 2005;96(2):291-3.

48. Gorelik G, Sawalha AH, Patel D, Johnson K, Richardson B. T cell PKCdelta kinase inactivation induces lupus-like autoimmunity in mice. Clin Immunol. 2015;158(2):193-203.

49. Mecklenbrauker I, Kalled SL, Leitges M, Mackay F, Tarakhovsky A. Regulation of B-cell survival by BAFF-dependent PKCdeltamediated nuclear signalling. Nature. 2004;431(7007):456-61. 
50. Gorelik G, Fang JY, Wu A, Sawalha AH, Richardson B. Impaired T cell protein kinase $\mathrm{C}$ delta activation decreases ERK pathway signaling in idiopathic and hydralazine-induced lupus. J Immunol. 2007;179(8):5553-63.

51. Gorelik GJ, Yarlagadda S, Patel DR, Richardson BC. Protein kinase Cdelta oxidation contributes to ERK inactivation in lupus T cells. Arthritis Rheum. 2012;64(9):2964-74.

52. Katz U, Zandman-Goddard G. Drug-induced lupus: an update. Autoimmun Rev. 2010;10(1):46-50.

53. Zhang X, Ma H, Huang J, Dai Y. Characterization of the phosphoproteome in SLE Patients. PLoS One. 2012;7(12), e53129.

54. Uddin S, Sassano A, Deb DK, Verma A, Majchrzak B, Rahman A, et al. Protein kinase C-delta (PKC-delta) is activated by type I interferons and mediates phosphorylation of Stat1 on serine 727. J Biol Chem. 2002;277(17):14408-16.

55. Yanase N, Hayashida M, Kanetaka-Naka Y, Hoshika A, Mizuguchi J. PKC-delta mediates interferon-alpha-induced apoptosis through c-Jun NH(2)-terminal kinase activation. BMC Cell Biol. 2012;13:7.

56. Huang X, Yang N, Ou X, Li D, Wang Z, Xie Q, et al. Sequential activation of protein kinase $\mathrm{C}$ delta and JNK is required for interferon-alpha-induced expression of IFIT4. Cell Signal. 2008;20(1):112-9.

57. Sharif MN, Tassiulas I, Hu Y, Mecklenbrauker I, Tarakhovsky A, Ivashkiv LB. IFN-alpha priming results in a gain of proinflammatory function by IL-10: implications for systemic lupus erythematosus pathogenesis. J Immunol. 2004;172(10):6476-81.

58. Kiykim A, Ogulur I, Baris S, Salzer E, Karakoc-Aydiner E, Ozen $\mathrm{AO}$, et al. Potentially beneficial effect of hydroxychloroquine in a patient with a novel mutation in protein kinase Cdelta deficiency. $\mathrm{J}$ Clin Immunol. 2015;35(6):523-6.

59. Hartwig JH, Thelen M, Rosen A, Janmey PA, Nairn AC, Aderem A. MARCKS is an actin filament crosslinking protein regulated by protein kinase $\mathrm{C}$ and calcium-calmodulin. Nature. 1992;356(6370): 618-22.

60. Suematsu S, Matsuda T, Aozasa K, Akira S, Nakano N, Ohno S, et al. IgG1 plasmacytosis in interleukin 6 transgenic mice. Proc Natl Acad Sci U S A. 1989;86(19):7547-51.

61. Lisnevskaia L, Murphy G, Isenberg D. Systemic lupus erythematosus. Lancet. 2014.

62. Cervera R, Khamashta MA, Hughes GR. The Euro-lupus project: epidemiology of systemic lupus erythematosus in Europe. Lupus. 2009;18(10):869-74.

63. Aggarwal A, Srivastava P. Childhood onset systemic lupus erythematosus: how is it different from adult SLE? Int J Rheum Dis 2014.

64. Yong PF, Thaventhiran JE, Grimbacher B. "A rose is a rose is a rose," but CVID is Not CVID common variable immune deficiency (CVID), what do we know in 2011? Adv Immunol. 2011;111:47-107.

65. Alangari A, Alsultan A, Adly N, Massaad MJ, Kiani IS, Aljebreen A, et al. LPS-responsive beige-like anchor (LRBA) gene mutation in a family with inflammatory bowel disease and combined immunodeficiency. J Allergy Clin Immunol. 2012;130(2):481-8.
66. Davies EG, Thrasher AJ. Update on the hyper immunoglobulin M syndromes. Br J Haematol. 2010;149(2):167-80.

67. Ombrello MJ, Remmers EF, Sun G, Freeman AF, Datta S, TorabiParizi P, et al. Cold urticaria, immunodeficiency, and autoimmunity related to PLCG2 deletions. N Engl J Med. 2012;366(4):330-8.

68. Zhou Q, Lee GS, Brady J, Datta S, Katan M, Sheikh A, et al. A hypermorphic missense mutation in PLCG2, encoding phospholipase Cgamma2, causes a dominantly inherited autoinflammatory disease with immunodeficiency. Am J Hum Genet. 2012;91(4): 713-20.

69. Gathmann B, Mahlaoui N, for C, Gerard L, Oksenhendler E, Warnatz K, et al. Clinical picture and treatment of 2212 patients with common variable immunodeficiency. J Allergy Clin Immunol. 2014.

70. Wehr C, Kivioja T, Schmitt C, Ferry B, Witte T, Eren E, et al. The EUROclass trial: defining subgroups in common variable immunodeficiency. Blood. 2008;111(1):77-85.

71. Warnatz K, Denz A, Drager R, Braun M, Groth C, Wolff-Vorbeck $\mathrm{G}$, et al. Severe deficiency of switched memory B cells (CD27(+ ) $\operatorname{IgM}(-) \operatorname{IgD}(-))$ in subgroups of patients with common variable immunodeficiency: a new approach to classify a heterogeneous disease. Blood. 2002;99(5):1544-51.

72. Foerster C, Voelxen N, Rakhmanov M, Keller B, Gutenberger $\mathrm{S}$, Goldacker $\mathrm{S}$, et al. B cell receptor-mediated calcium signaling is impaired in B lymphocytes of type Ia patients with common variable immunodeficiency. J Immunol. 2010;184(12): 7305-13.

73. Everett KL, Bunney TD, Yoon Y, Rodrigues-Lima F, Harris R, Driscoll PC, et al. Characterization of phospholipase C gamma enzymes with gain-of-function mutations. J Biol Chem. 2009;284(34):23083-93.

74. Sthoeger Z, Sharabi A, Mozes E. Novel approaches to the development of targeted therapeutic agents for systemic lupus erythematosus. J Autoimmun 2014.

75. Lo B, Zhang K, Lu W, Zheng L, Zhang Q, Kanellopoulou C, et al. AUTOIMMUNE DISEASE. Patients with LRBA deficiency show CTLA4 loss and immune dysregulation responsive to abatacept therapy. Science. 2015;349(6246):436-40.

76. Laplante M, Sabatini DM. mTOR signaling in growth control and disease. Cell. 2012;149(2):274-93.

77. Chun HY, Chung JW, Kim HA, Yun JM, Jeon JY, Ye YM, et al. Cytokine IL-6 and IL-10 as biomarkers in systemic lupus erythematosus. J Clin Immunol. 2007;27(5):461-6.

78. Slatter MA, Gennery AR. Advances in hematopoietic stem cell transplantation for primary immunodeficiency. Expert Rev Clin Immunol. 2013;9(10):991-9.

79. Griffith LM, Cowan MJ, Notarangelo LD, Kohn DB, Puck JM, Pai SY, et al. Primary immune deficiency treatment consortium (PIDTC) report. J Allergy Clin Immunol. 2014;133(2):335-47.

80. Mukherjee S, Thrasher AJ. Gene therapy for PIDs: progress, pitfalls and prospects. Gene. 2013;525(2):174-81. 